\title{
WORLD FEDERATION OF NEUROSURGICAL SOCIETIES - WFNS
}

\author{
MESSAGE FROM THE PRESIDENT
}

\section{Dear colleagues,}

WFNS continues to flourish with its various functions and obligations. It shares vast knowledge, collected from neurosurgical colleagues, worldwide. WFNS, as a widespread net of societies, represents the strength of the international community of neurosurgery and serves as the intellectual spirit of brain surgery. The promotion of both high-tech neurosurgery, with a glimpse into the future, and expert advice are fundamental challenges of the future. I am proud to be the President of the WFNS and to represent the international family of neurosurgeons, together with the Officers of WFNS and I am delighted that such a great number of neurosurgeons all over the world have such a close contact. My obligations as President of WFNS are a constant challenge and I continue to find neurosurgery more and more fascinating. Organized activities will dominate the year 2000 and we are planning some very exciting events for the millennium. The courses taking place under the patronage of WFNS continue to be popular and extremely successful. Our aim is to provide expert advice and to develop a universal set of instruments for neurosurgical units in developing countries, sufficiently on time, for them to be used at the turn of the millennium. Our goal to provide neurosurgeons in units with low budgets, with a neurosurgical set of instruments is proceeding at a pace far beyond my expectations. I am deeply grateful to all colleagues, worldwide, who have assisted me in this unique venture.

Prof. Madjid Samii, MD

President, WFNS 